\title{
Flavia Freidenberg y Betilde Muñoz-Pogossian \\ (Eds.), Reformas a las Organizaciones de Partidos en América Latina (1978-2015), México, OEA/UNAM/PUCP/SAAP, 2016, 533 pp.
}

Perfiles Latinoamericanos, 26(51)

2018 | pp. 419-426

DOI: $10.18504 / \mathrm{pl} 2651-018-2018$

\section{$R$}

eformas a las Organizaciones de Partidos en América Latina (1978-2015), obra editada por Flavia Freidenberg (IIJ, UNAM) y Betilde Muñoz-Pogossian (OEA), reúne a académicos, funcionarios de organismos de cooperación internacional y a consejeros y jueces electorales con el objetivo de analizar desde diferentes perspectivas las implicaciones que han tenido las reformas de los últimos cuarenta años en la región sobre los partidos políticos como organizaciones. Este trabajo, en consecuencia, tiene dos aciertos. Se ocupa de uno de los temas fundamentales en las democracias contemporáneas, y lo hace desde el punto de vista tanto de expertos imbuidos en el análisis teórico y comparado, como de funcionarios con experiencia en la aplicación práctica de las normas.

En el libro se abordan cuatro temas generales: selección de candidaturas, cuotas de género y promoción de liderazgo femenil, financiamiento, y sistemas electorales. En cada capítulo se evalúa el impacto de las reformas sobre las organizaciones de partidos en alguno de esos aspectos y se identifican las buenas prácticas para futuras agendas legislativas.

El capítulo inicial, "La reina de las reformas: Las elecciones internas a las candidaturas presidenciales en América Latina” es de Flavia Freidenberg. Allí la autora sostiene que fue a finales de los noventa que se introdujeron reformas en las elecciones internas de los partidos, lo que provino de la intención de producir legitimidad, por presiones de organismos internacionales, etc., con resultados diversos que van desde causar división en la organización visibilizando el conflicto interno, hasta el reforzamiento de las élites. Freidenberg concluye que el diseño con más probabilidades de éxito, en términos de democracia interna, es aquel donde las elecciones internas son no obligatorias, cerradas a militantes 
con un año de antigüedad, supervisadas, financiadas, organizadas por el órgano electoral y cuyos resultados sean vinculantes.

En "La nominación intrapartidista de candidatos: Una visión desde la justica electoral", María del Carmen Alanís defiende la necesidad de contar con medios endógenos y exógenos de resolución de conflictos intrapartidarios. Alanís muestra cómo a partir de instrumentos internacionales, como la Carta Democrática Interamericana, los Estados quedan obligados a proteger el derecho de asociación en la medida en que este no solape la violación de derechos de los militantes. La autora sostiene que la tradición jurídica en América Latina se caracteriza por su amplia regulación de la vida intrapartidista, tutelada por tribunales electorales especializados. Desde su perspectiva, este constituye el modelo más adecuado dado que permite el control estatal de los partidos.

Cesar Astudillo, por su parte, desarrolla el tema de las candidaturas independientes desde la lógica del derecho de participación política. En su capítulo, "La postulación de candidaturas partidistas e independientes en América Latina en el contexto de los derechos de participación política", discute la razonabilidad de la afiliación a un partido en su sentido de obstáculo para el ejercicio del derecho del sufragio pasivo. Astudillo defiende la idea de que condicionar el derecho de ser votado al aval de algún partido es discriminatorio y violatorio del derecho de libertad ideológica y de asociación en su vertiente negativa (no asociarse). Y puntualiza que si bien es cierto que en los setenta se justificaba otorgar el monopolio de la representación de los partidos con el objetivo de construir un sistema democrático, actualmente eso debe cuestionarse dado el entorno de exigencia ciudadana de otros espacios de participación.

La aportación de Salvador Romero, "Primarias en Honduras: Siguiendo las huellas de un sistema original (1985-2013)", consiste en exponer las características y los problemas de la utilización de métodos abiertos para elegir candidatos en los partidos hondureños. Este autor reseña cómo las primarias fueron adoptadas por primera vez en 1989 a manera de mecanismo idóneo para sortear una crisis política en el Partido Liberal, sin considerársele una forma de democracia interna. Y, dado su éxito, para 1997, el Partido Nacional también las adopta. Las primarias en este país son voluntarias, simultáneas, abiertas, de una vuelta, con cuota femenina, vinculatorias, administradas y calificadas por el tribunal electoral, financiadas con fondos privados y utilizadas para todos los cargos electivos. Romero afirma que este mecanismo se ha consolidado y legitimado en Honduras, aunque no esté libre de problemas. El personalismo y el clientelismo son todavía los retos principales para llevar estos procesos a buen puerto.

El capítulo "Fundamentos, alcances y efectos de la reforma argentina al sistema de selección de candidaturas nacionales en la Ley de Reforma Política de 2009" de Alejandro Tullio contiene un análisis de las reglas para elegir candi- 
datos en Argentina. Tullio sostiene que la crisis de legitimidad y representación de los años noventa incentivó la reforma electoral de 2002, la cual instauró un sistema de elecciones internas abiertas no obligatorias y eliminó el umbral del $2 \%$ necesario para que un partido conservara el registro legal. Como resultado, el sistema de partidos se fragmentó de tal manera que se llegaron a registrar 697 partidos a nivel federal. Después de las elecciones de 2009, se reformó el sistema de elección de candidatos y se estableció un sistema de primarias abiertas, simultáneas, obligatorias con voto secreto y cuyo escrutinio corresponde a la justicia electoral; además de que se condicionó el competir en elecciones a la obtención de al menos al 1.5\% de los votos emitidos. El autor arguye que debido a lo novedoso de esta reforma no es posible un análisis acabado de su impacto y entonces se limita a subrayar que en los últimos años se ha observado una alta participación ciudadana.

Mariana Caminotti, autora de "Cuotas de género y paridad en América Latina: Mujeres, partidos políticos y Estado", explica que la introducción de cuotas y paridad de género comenzó en los años noventa, aunque actualmente esto se ha generalizado y el impacto ha sido notable. Así, el promedio de legisladoras nacionales pasó del 9\% en 1990 al 25\% en 2014. A pesar de estos datos, Caminotti afirma que la presencia femenina en la política aún enfrenta serios retos, pues en los hechos las mujeres sufren el incumplimiento de las leyes, acoso y violencia. A su parecer, las medidas de discriminación positiva deben acompañarse de esfuerzos que abonen a la igualdad real y multidimensional de las mujeres, en los ámbitos económico, sexual, reproductivo y social.

En su capítulo "Modelos de reclutamiento en los partidos políticos: Reformas, retos y buenas prácticas para la representación de las mujeres", Betilde Muñoz-Pogossian subraya que en América Latina solo cinco países han adoptado la paridad de género en candidaturas: Bolivia, Costa Rica, Ecuador, Nicaragua y México; solo cuatro tienen financiamiento político específico para las mujeres: México, Brasil, Costa Rica y Panamá, y únicamente Bolivia ha aprobado leyes para sancionar el acoso y la violencia política contra las mujeres. Para lidiar con este problema, la autora plantea diversas propuestas que van desde la organización de actividades para concientizar a la población y a los partidos sobre este problema, hasta la aplicación de sanciones cuando se infrinjan las normas.

Margarita Batlle, al analizar la situación de las mujeres en los partidos colombianos en su texto, "Partidos políticos y participación de las mujeres en Colombia: ¿Hacia estructuras más inclusivas?”, consigna que en los últimos veinte ańos la participación de las mujeres en el Congreso pasó del 8 al 21\%, y que en los últimos años se han observado importantes avances legislativos. Batlle señala que fue en 2014 cuando se aplicó por primera vez la ley de cuotas a nivel nacional y se contemplaron incentivos financieros para los partidos 
que colocaran el mayor número de mujeres en cargos de elección popular. La evaluación de Batlle concluye que la cultura política patriarcal representa el obstáculo más grande para la inclusión de las mujeres.

En el capítulo "La participación política de la mujer en Argentina", Alberto Dalla resalta los avances en la inclusión de las mujeres para cargos electivos en Argentina. El autor arguye que este país se encuentra entre los primeros lugares de representación femenina en el mundo con 37 y $40 \%$ de mujeres en las Cámaras baja y alta, respectivamente. Sin embargo, Dalla considera que persisten retos serios, entre los que destaca la necesidad de lograr una representación cualitativa y no solo cuantitativa de los intereses femeninos.

Luis Antonio Sobrado, en "El Tribunal Supremo de Costa Rica: Concretando la cuota femenina y transitando a la paridad de género", arguye que las decisiones del juez electoral han abonado al avance de la inclusión de las mujeres en la política costarricense; pues si bien la ley de 1996 obligaba a los partidos a presentar al menos el $40 \%$ de mujeres en las candidaturas y en las delegaciones de sus asambleas intrapartidarias, fueron las decisiones jurisprudenciales lo que los obligó a cumplir con esa cuota dentro de los "Puestos elegibles del partido". Asimismo, Sobrado destaca que la ley de 2009, que determina la paridad y el orden de alternancia en las listas, se aprobó gracias a una propuesta del Tribunal Supremo.

En "Para llegar a tiempo: Apuntes sobre la regulación del financiamiento político en América Latina”, Kevin Casas-Zamora y Daniel Zovatto explican que el dinero en política es un tema en particular sensible en América Latina debido a la enorme desigualdad social y a la presencia del crimen organizado. Los riesgos que estos autores identifican los relacionan con la utilización de dinero ilegal, con la compra de influencias y con conflictos de interés en contribuciones privadas. Además, puntualizan, se generaría inequidad electoral y se perdería credibilidad. Estos autores sostienen que una buena regulación debe incluir prohibiciones a la entrada de recursos y financiamiento estatal. Y señalan que la experiencia comparada muestra que el financiamiento público es adecuado cuando se acompańa de campañas cortas, restricciones a la emisión de publicidad y de incentivos fiscales para pequeños donantes. Terminan su aportación aconsejando aprovechar las crisis como oportunidades para introducir nuevos temas en la agenda pública y legislar pensando en el corto y largo plazos.

Claudio Fuentes y Mario Herrera, en el capítulo "Financiamiento de la política en América Latina: regulación y calidad de la democracia", se ocupan de las características de la regulación del financiamiento a partidos en la región y proponen varias medidas para enfrentar sus desafíos. Como apuntan los autores, la mayoría de los países contemplan la asignación de financiamiento público 
permanente a partidos y han establecido límites al gasto electoral y formas de control. Fuentes y Herrera argumentan que para evitar distorsiones que perjudiquen a la democracia convendría generalizar un modelo en donde se prohíban las donaciones privadas directas, se conformen y refuercen mecanismos de control, exista transparencia, acceso equitativo en los medios de comunicación y se regulen actividades aledańas, por ejemplo, las encuestas, las campañas disfrazadas, etcétera.

En "Financiamiento a los partidos políticos y acceso a los medios de comunicación en México", Ciro Murayama examina el modelo de financiamiento de los partidos políticos en México y concluye que este es predominantemente público y tiene límite de gastos, acceso a medios en tiempos oficiales, fiscalización exhaustiva y máxima publicidad. Al decir de Murayama, el propósito ha sido lograr contiendas equitativas y procurar la independencia de partidos y candidatos frente a grupos de poder, un diseño que ha sido resultado de las respuestas a diferentes crisis políticas.

Daniel Buquet se encarga de explorar en los efectos de los sistemas electorales sobre la organización interna de los partidos. En "Presidencialismo, reforma electoral y estructura interna partidaria", advierte que elementos como el tipo de candidatura, el voto, la fórmula o el timing electoral tienen efectos indirectos, pues los partidos se adaptan para ser más eficaces electoralmente; mientras que otros aspectos tienen un efecto directo, dado que pueden obligar a los partidos a contar con una estructura determinada o a desarrollar sus procesos internos siguiendo un método específico.

En su aportación, "Efectos institucionales sobre el desarrollo organizativo de los partidos políticos en América Latina”, María do Socorro Sousa Braga analiza los efectos de los cambios institucionales recientes sobre los partidos en países gobernados por la izquierda: Chile, Brasil, Bolivia y Venezuela. La autora encuentra que donde gobierna la izquierda radical (Bolivia y Venezuela) la duración del mandato se amplió y las restricciones a la reelección fueron eliminadas. Ello ha llevado a la concentración de poder en el ejecutivo y a la reducción del espacio político para la oposición. Mientras que en Brasil y Chile el ciclo electoral se volvió concurrente y aunque también hay mayor concentración de poder en el ejecutivo, hay al mismo tiempo mayor participación de diversos segmentos de la población.

Alejandro Luna Ramos, en "Reformas orientadas a la transparencia, las elecciones y los partidos políticos en México", defiende la idea de que el ejercicio efectivo de los derechos políticos requiere tener garantizada la posibilidad de acceder a la información pública. Y al respecto, expone que desde 2008 los partidos políticos en México deben cumplir con ciertas obligaciones de transparencia, pero es apenas en 2014 cuando se vuelven sujetos obligados. En este 
contexto, el tribunal electoral, como órgano garante, ha resuelto los desacuerdos a partir del principio de máxima publicidad, restringiéndolo solo cuando se pone en riesgo la seguridad nacional o de terceros.

En "Una reforma sin plan: Cuando los partidos peruanos se multiplican", Fernando Tuesta afirma que el mal diseño de las reformas electorales en Perú empeoró el problema que pretendían afrontar. Después del fujimorismo (19891992), el fraccionalismo y el personalismo en el sistema de partidos eran notables. Las reformas electorales aprobadas pretendían resolver este problema, sin embargo, ello no fue así porque no se acompañaron las exigencias de registro con mecanismos efectivos de validación. La atomización partidaria se exacerbó con el surgimiento de partidos regionales, y en el Congreso se multiplicaron las agendas políticas no integradas y de corto plazo. El problema, dice Tuesta, es que las reformas se han desarrollado de manera pragmática, sin considerar la integridad de sus elementos.

José Puyana, Mario Ruiz y Daniela Vargas, en "Reformas políticas en Colombia (2003-2011): Avances y efectos sobre la organización interna de los partidos", evidencian que la Constitución colombiana de 1991 permitió la fragmentación del sistema de partidos, lo que dio lugar a que se llegaran a contar más de setenta organizaciones a finales de los noventa. Como reacción, en 2003 se estableció un umbral de 2\% que en 2009 se eleva a 3\%, lo que redujo a trece el número de partidos. Por otra parte, gracias a los escándalos de 2007, en 2009 se determinó que el partido que perdiera una curul debido a vínculos con la delincuencia no podría recuperarla. Mientras que en 2011 se aprobaron las primeras reglas de democracia intrapartidaria y se dispuso que 5\% de financiamiento se repartiera con base en el número de mujeres electas y otro $5 \%$ con base en el número de jóvenes electos. Los avances han sido considerables, aunque hay temas pendientes, como la necesidad de concretar el registro de militantes o de dotar de capacidad técnica y operativa al Consejo Nacional Electoral para su labor de fiscalización.

El libro cierra con el trabajo de Yuri Beltrán, "La influencia del voto migrante sobre los partidos y los sistemas de partidos latinoamericanos". Allí el autor observa que desde hace cincuenta años en la región se comenzó a legislar el voto en el extranjero, lo que se aceleró con el regreso a la democracia. Es así que los partidos han tenido que adaptarse, incorporando este tema en sus programas y permitiendo la afiliación y la participación extraterritorial para la integración de sus órganos directivos. Entre los temas pendientes, Beltrán propone dar paso a las campañas electorales en el extranjero, generalizar la circunscripción especial y asignar recursos para la politización de la migración.

Los trabajos recogidos en esta obra ofrecen un examen riguroso de los temas más importantes en la discusión latinoamericana actual sobre la legislación en 
materia de partidos políticos. Al combinar estudios de caso con análisis comparados se obtiene una imagen más completa de las reformas aprobadas en la región y de su impacto. Por ello este libro es una lectura obligada para académicos y para aquellos involucrados en la aprobación y la aplicación de las normas que afectan a los partidos políticos.

No obstante, debe señalarse que esta publicación adolece de una desafortunada omisión, ya que carece de un análisis de conjunto que integre las conclusiones y propuestas presentadas en cada uno de los capítulos. Así, a pesar de reunir visiones de distintos actores (académicos, funcionarios de agencias internacionales de cooperación y autoridades electorales), es evidente la falta de diálogo entre ellas.

De la lectura de esta obra se concluye que en América Latina los partidos políticos son sujetos de una creciente y rigurosa regulación jurídica. Al parecer tienen razón quienes han advertido que la visión clásica liberal de los partidos como organizaciones privadas que no deben sufrir la intromisión del Estado está abandonándose por otra que los concibe como "agencias de interés público" y legitima la intervención estatal en su funcionamiento (Biezen, 2004). El financiamiento público de los partidos tiende a constituir una parte cada vez más importante de sus gastos y la legislación que los constriñe a comportarse internamente de un determinado modo y que permite la intervención de los órganos jurisdiccionales del Estado en su vida interna también se ha fortalecido.

Por otra parte, es enriquecedor comparar lo que pasa en América Latina con lo que sucede en otras democracias de más larga data, para las que el financiamiento público se ha ido diluyendo (Dwyre, 2015) y la regulación de su vida interna es de menor alcance (Biezen $\&$ Romée, 2013). Es evidente que los problemas propios de América Latina obligan a buscar soluciones distintas. La pobreza y desigualdad generalizadas conducen a buscar en el financiamiento público una vía para evitar que el poder económico capture la política; y el constante abuso de poder, oligarquización y discriminación por género dentro de los partidos, vuelven necesario normar la vida interna de los partidos en sentido democrático y permitir la intervención de tribunales estatales independientes.

El camino está definido, pero como los autores de esta obra explican, debe ajustarse la legislación actual permitiendo siempre una mayor transparencia y rendición de cuentas sin olvidar que las instituciones importan pero no determinan el resultado. Sin una ciudadanía atenta y exigente, sin autoridades electorales dispuestas a hacer valer la ley, y sin partidos y líderes políticos comprometidos con la democracia, será imposible mejorar la calidad de las democracias latinoamericanas. 


\section{Referencias}

Biezen, I. van. (2004). Political parties as public utilities. Party Politics, 10(6), 701-722

Biezen, I. van \& Romée, D. (2013). Shaping intra-party democracy: On the legal regulation of internal party organizations. En Cross, W. \& Katz, R. (Eds.). The challenges of intra-party democracy (pp. 27-48). Oxford: Oxford University Press.

Dwyre, D. (2015). Campaign finance deregulation in the United States: What has changed and why does it matter?. En Boatright, R. (Ed.). The deregulatory moment? A Comparative perspective on changing campaign finance laws (pp. 33-70). USA: University of Michigan Press.

\section{Jorge Gerardo Flores Díaz}

* Candidato a doctor en Ciencias Políticas y Sociales por la Universidad Nacional Autónoma de México. 